\title{
Biofertilizer for sustainable rice production and reduction of environmental pollution
}

\begin{abstract}
Rice is the staple food for more than half of the worldôs population. Rice production needs a huge amount of chemical fertilizer application, especially urea, which is one of the causes of global warming and groundwater pollution. Nitrous oxide emission and nitrate leaching can be reduced only via the reduction of chemical nitrogen fertilizer use or by developing a mechanism whereby the plant can get atmospheric nitrogen directly without any loss in the soil system. After nitrogen the second most important nutrient is phosphorus. Phosphorus availability is very much $\mathrm{pH}$ dependent. It may prevail in the soil but may not be bioavailable to the plant. In this case a group of microorganisms can help to make bioavailable phosphorus and simultaneously reduce use of chemical phosphorus fertilizer. Biological nitrogen fixation by the free-living bacteria and solubilization of insoluble organic and inorganic phosphorus by microorganisms are well documented. Free-living diazotroph, phosphate solubilizing bacteria, and plant growth-promoting bacterial strains containing biofertilizer are commonly used for the production of field crops. Biofertilizer containing these microbes will supplement the need for chemical fertilizer and will ensure a healthy environment. The objective of the chapter is to discuss briefly the scope and potential of biofertilizer containing free-living diazotrophs, phosphate-solubilizing bacteria, and plant growth-promoting rhizobacteria for sustainable rice production in an ecofriendly environment.
\end{abstract}

Keyword: Biological nitrogen fixation; Diazotrophs; Global warming; Fertilizer; PGPR; Phosphate-solubilizing bacteria 